\title{
Characteristics of Chinese smokers with psychotic disorders and their predictors on smoking cessation in Hong Kong
}

\author{
Raymond K. S. Ho', Gina M. T. Lee', Patrick W. Y. Fok', Helen C. H. Chan', Joe K. W. Ching ${ }^{1}$
}

\begin{abstract}
INTRODUCtION People with psychotic disorders are associated with high prevalence of cigarette smoking and prevalence rates. Studies show that many smokers with psychotic disorders would like to stop smoking, yet the abstinence rate among them is low. Despite this significant public health problem, few studies have examined the characteristics of this group of smokers and the predictors of smoking cessation.

METHODS This is a retrospective chart review study. Case records of smokers who attended our smoking cessation clinic with and without psychotic disorders were reviewed. The outcome measure was self-reported 7-day point prevalence abstinence rate at week 26 . The basic demographic and biosocial characteristics of these smokers were analyzed.

RESULTS A total of 3671 case records were reviewed and 155 smokers with psychosis were identified. The independent predictors of smoking abstinence at week 26 were to improve performance in exercise and sports, greater confidence of quitting, and greater number of counselling sessions. The 7 -day point prevalence abstinence rate was $22.6 \%$ at 26 weeks.

CONCLUSIONS This study has demonstrated that many smokers with psychosis are able to quit smoking even with NRT and counselling and without use of oral medications. Health professionals need to pay greater attention to tobacco use by individuals with mental disorders. Every effort should be given to enhance their motivation, build up their confidence and to provide adequate counselling sessions.
\end{abstract}

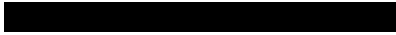

AFFILIATION

1 Tung Wah Group of Hospitals Integrated Centre on Smoking Cessation, Tsuen Wan, Hong Kong

CORRESPONDENCE TO

Raymond K. S. Ho. Tung Wah Group of Hospitals Integrated Centre on Smoking Cessation, 68 Chung On St, Tsuen Wan, Hong Kong. E-mail: rayhoks@yahoo.com.hk

\section{KEYWORDS}

smoking cessation, psychosis, predictors
\end{abstract}

Received: 23 September 2019 Revised: 16 November 2019

Accepted: 3 December 2019

\section{INTRODUCTION}

People with psychotic disorders are associated with high prevalence of cigarette smoking and prevalence rates, varying from $50 \%$ to $90 \%$ across studies ${ }^{1}$.

A recent meta-analysis of 42 studies across 20 countries reported that the odds of people with schizophrenia or schizoaffective disorder being current smokers were 5.3 times higher compared to the general population, with an average prevalence of $62 \%$. Such high rates of smoking among those with psychotic disorders may lead to a $20 \%$ reduction in life expectancy and also premature death caused by smoking related diseases ${ }^{2}$.
Studies show that many smokers with schizophrenia like to stop smoking, yet smoking cessation rates among these people are quite low. The cessation rates reported in meta-analyses were $9 \%$ for schizophrenia versus $14 \%$ to $49 \%$ for the general population ${ }^{3}$. Some experts explained that smoking might be a form of self-medication to correct for sensory and cognitive deficits and to alleviate negative symptoms in this group of people, and hence they are more inclined to smoke ${ }^{4}$. However, other factors might come into play, such as increase in nicotine dependence due to dysregulation of nicotine receptors in this population, motivation, 
and social factors ${ }^{5,6}$. In essence, there may be an interplay among these biological, psychological and social factors.

Despite the magnitude of the public health burden of smoking among people with psychotic disorders and that a sizeable proportion of people with psychotic disorders are willing to quit smoking, few studies have investigated the baseline characteristics of this group of smokers ${ }^{7-11}$. Such information may be important when designing smoking interventions for people with psychotic disorders. Many overseas studies have focused solely on schizophrenia and not on a wider spectrum of psychotic disorders. Melissa et al. ${ }^{12}$ have studied the predictors of abstinence focusing on the positive or negative symptoms of psychosis, neuropsychologic performance, the use of psychotropic drugs and a little on smoking behavior ${ }^{12}$. We are not aware of any local study on these smokers and we are not sure whether there are any ethnic and cultural differences between our Chinese population and other ethnic groups.

The present study aims: 1) to study the demographic, biosocial characteristics of Chinese smokers with psychotic disorder in a community setting and their smoking behaviours (cigarette consumption, years of smoking, severity of nicotine dependence, self-efficacy, reason to quit smoking, and the use of alcohol); 2) to assess the predictors on quitting; and 3) the effectiveness of using NRT in this group of smokers.

\section{METHODS}

In 2009, the Tung Wah Group of Hospitals (TWGHs) was commissioned by the Hong Kong SAR Government to provide a community-based smoking cessation service in Hong Kong. The Integrated Centre on Smoking Cessation (ICSC) of the TWGHs was then set up in different districts of Hong Kong to provide a free smoking-cessation service to Hong Kong citizens. An integrated model of counselling and pharmacotherapy was adopted ${ }^{13}$.

This is a retrospective chart review study. Case records of smokers who voluntarily attended an ICSC in different districts in Hong Kong from 1 April 2015 to 31 March 2016 were reviewed. The inclusion criteria of the chart review were Chinese adults aged $\geq 18$ years; currently diagnosed to have psychotic disorders by ICD-10 and limited to schizophrenia, schizoaffective disorders, and affective disorders with psychotic features. Patients with organic conditions causing psychosis, druginduced psychosis, acute psychotic disorders, being pregnant or breast feeding, were excluded.

The smoking subjects were recruited via smoking cessation hotlines, referral from healthcare professionals, or self-referral. After informed consent, basic demographic data, smoking related variables, psychosocial factors and self-perceived efficacy on smoking cessation, use of alcohol and associated AUDIT score, were collected through a structured questionnaire, used in other local studies ${ }^{14}$. Confidentiality of personal data was ensured.

All participants received at least half an hour of intensive face-to-face counselling and assessment in the first intake, and pharmacotherapy was prescribed after clinical assessment by a family physician. Weekly counselling sessions were given initially until participants were able to abstain from smoking, and this was followed by counselling at least every 2 weeks until completion of treatment. The number of counselling sessions and defaulters for counselling were recorded. Exhaled carbon monoxide (CO) measurement with a Bedfont smokerlyser was conducted in every clinic visit. Counselling was conducted by experienced social workers who had been trained in tobacco cessation counselling. Phone counselling was given when the participants could not make the visit. Counselling would incorporate elements of both cognitive behavioural therapy and motivational interviewing ${ }^{15}$. Clients were then contacted again by phone at week 26 to ascertain abstinence from smoking. The medications provided by ICSC included a 12-week course of nicotine replacement therapy (NRT) or non-NRT, prescribed according to the clients' personal preferences and clinical conditions after a thorough explanation by family physicians. NRT included nicotine patches, gums and lozenges, and the oral medications were Varenicline and Bupropion.

\section{Outcome measure}

The outcome measure was self-reported 7 -day point prevalence abstinence rate at week 26 . Clients who had defaulted or failed to be contacted to ascertain smoking status were considered not having quit. 


\section{Statistical analysis}

Data management and analysis were performed using the Statistical Package for the Social Sciences (Windows version 22.0; SPSS Inc, Chicago [IL], US). Univariate logistic regression was used for all studied predictors. All predictors with a reported p-value $<0.1$ were included in multiple logistic regression analysis. Backward elimination was used in the multivariate analysis to identify independent predictors of abstinence as well as to calculate the adjusted odds ratio (AOR) and 95\% confidence interval (CI). All statistical analyses were two-tailed tests and a p-value $<0.05$ was considered statistically significant.

\section{RESULTS}

\section{Characteristics of smokers}

A total of 3671 case records were reviewed and 155 smokers with psychosis were identified. The basic characteristics of these smokers are summarized in Table 1. Among the 155 smokers, 99 (63.9\%) were male and $56(36.1 \%)$ were female. The mean age was 43.55 years $(\mathrm{SD}=11.96)$. The average cigarette consumption per day was $21.99(\mathrm{SD}=10.03)$. The mean Fagerström score was $6.55(\mathrm{SD}=1.98)$. The mean AUDIT score for alcohol was $1.77(\mathrm{SD}=4.29)$, with the great majority $(94.2 \%)$ scoring $\leq 8$, and $29.3 \%$ had smokers in the same household. Most of the smokers had rated high importance on quitting smoking with a score of $81.83 / 100(\mathrm{SD}=19.54)$.

The comparison of the characteristics between smokers with and without psychosis is given in Table 2. The significant differences between the two groups in the study period were that in the psychotic group, there were more singles, less personal income, lower education level, more unemployed, consuming more cigarettes per day with higher Fagerström score and lower AUDIT score. The 7 -day point prevalence abstinence rate of smokers who had psychosis was $22.6 \%(n=35)$ at week 26 compared to $42.7 \%(\mathrm{~N}=1500)$ of smokers who did not have psychosis, and the difference was clinically significant $(\mathrm{p}<0.001)$. All smokers in this cohort happened to have received nicotine replacement therapy and none received non-NRT oral medication. The mean number of counselling sessions was 5.65 ( $\mathrm{SD}=3.08$ ).

\section{Predictors of abstinence at 26 weeks}

Univariate logistic regression was used to explore the
Table 1. Demographics and characteristics of psychotic subjects $(\mathrm{N}=155)$

$\begin{array}{lr}\text { Characteristics } & \text { in (\%o) } \\ \text { Age (years) } & 43.55(11.96)\end{array}$

\section{Gender}

Male

99 (63.9)

Female

$56(36.1)$

Marital status

Single

$74(48.1)$

Married/cohabiting

52 (33.8)

Widowed

Divorced/separated

24 (15.6)

Education level

$\begin{array}{ll}\text { Junior secondary (S3) or below } & 68(45.9) \\ \text { Senior secondary (S4-S7) } & 58(39.2) \\ \text { Post-Secondary or above } & 22(14.9) \\ \text { Employed } & 71(46.4)\end{array}$

Personal income (HK\$)

$<9999$

67 (68.4)

10000-19999

29 (29.6)

20000-29999

2 (2.0)

Cigarettes per day

$21.99(10.03)$

0-10

21 (13.5)

11-20

80 (51.6)

21-30

32 (20.6)

$\geq 31$

22 (14.2)

Fagerström score

Low (0-3)

6.55 (1.98)

Moderate (4-5)

$12(7.7)$

High (6-10)

31 (20.0)

$112(72.3)$

Audit score

$1.77(4.29)$

$\leq 8$

$>8$

$146(94.2)$

9 (5.8)

Self-reported feeling depressed 58 (37.7) in the past 2 weeks

Smokers at home

$44(29.3)$

Self-assessment of efficacy in quitting

Importance

$81.83(19.54)$

Confidence

$59.22(24.04)$

73.97 (21.85)

Difficulty

Exchange rate: $1 \mathrm{US} \$=7.8 \mathrm{HK} \$$

potential predictors of quitters at week 26 . Variables with $\mathrm{p}$-value $<0.01$ were included in the further multiple regression analysis. Amongst the smoking- 
Table 2. Comparison of the demographic, smoking behaviour and intervention between smokers with or without psychosis

\begin{tabular}{|c|c|c|c|c|c|}
\hline & $\begin{array}{l}\text { Psychotic } \\
(\mathrm{n}-155)\end{array}$ & $\begin{array}{l}\text { Von-Psychotic } \\
\quad(\text { (n-3516) }\end{array}$ & t-value & $\chi^{2}$ & p \\
\hline \multicolumn{6}{|l|}{ Age (years) } \\
\hline Mean (SD) & $43.55(11.96)$ & $42.31(12.45)$ & 1.22 & & 0.22 \\
\hline Range & 21-87 & 18-89 & & & \\
\hline \multicolumn{6}{|l|}{ Gender, n (\%) } \\
\hline Male & $99(63.9)$ & $2718(77.3)$ & & 15.01 & $<0.001$ \\
\hline Female & $56(36.1)$ & $798(22.7)$ & & & \\
\hline Marital status, n (\%) & & & & 41.91 & $<0.001$ \\
\hline Married/cohabiting & $52(33.8)$ & 2073 (59.8) & & & \\
\hline Education level, n (\%) & & & & 12.60 & 0.002 \\
\hline Junior secondary (S3) or below & $68(45.9)$ & $1030(32.1)$ & & & \\
\hline Senior secondary (S4-S7) & $58(39.2)$ & $1504(46.9)$ & & & \\
\hline Post-Secondary or above & $22(14.9)$ & $672(21.0)$ & & & \\
\hline Employed, n (\%) & $71(46.4)$ & $2793(81.0)$ & & 107.50 & $<0.001$ \\
\hline \multicolumn{6}{|l|}{ Personal income (HK\$), n (\%) } \\
\hline$<9999$ & $67(68.4)$ & $490(17.4)$ & & 165.84 & $<0.001$ \\
\hline 10000-19999 & $29(29.6)$ & $1382(48.9)$ & & & \\
\hline 20000-29999 & $2(2.0)$ & $570(20.2)$ & & & \\
\hline$\geq 30000$ & 0 & $382(13.5)$ & & & \\
\hline Smokers at home, $\mathrm{n}(\%)$ & $44(29.3)$ & $1106(32.1)$ & & 0.51 & 0.47 \\
\hline \multicolumn{6}{|l|}{ Cigarettes per day } \\
\hline Mean (SD) & $21.99(10.03)$ & $18.18(8.80)$ & 5.24 & & $<0.001$ \\
\hline Range & $3-60$ & 4 & & & \\
\hline \multicolumn{6}{|l|}{ Fagerström score } \\
\hline Mean (SD) & $6.55(1.98)$ & $5.24(2.40)$ & 6.69 & & $<0.001$ \\
\hline Range & $1-10$ & $0-10$ & & & \\
\hline \multicolumn{6}{|l|}{ Audit score } \\
\hline Mean (SD) & $1.77(4.29)$ & $4.04(5.50)$ & -5.07 & & $<0.001$ \\
\hline Range & $0-31$ & $0-39$ & & & \\
\hline \multicolumn{6}{|l|}{ Self-assessment of efficacy in quitting } \\
\hline \multicolumn{6}{|l|}{ Importance } \\
\hline Mean (SD) & $81.83(19.54)$ & 80.46 (18.03) & & & \\
\hline Range & $0-100$ & $0-100$ & 0.92 & & 0.36 \\
\hline \multicolumn{6}{|l|}{ Confidence } \\
\hline Mean (SD) & $59.22(24.04)$ & $61.40(22.51)$ & & & \\
\hline Range & $0-100$ & $0-100$ & -1.17 & & 0.24 \\
\hline \multicolumn{6}{|l|}{ Difficulty } \\
\hline Mean (SD) & $73.97(21.85)$ & $73.78(21.50)$ & & & \\
\hline Range & $0-100$ & $0-100$ & 0.11 & & 0.91 \\
\hline \multicolumn{6}{|l|}{ Interventional variables } \\
\hline Counselling sessions Mean (SD) & $5.65(3.08)$ & $5.44(2.41)$ & 1.06 & & 0.29 \\
\hline $\begin{array}{l}\text { Self-reported } 7 \text {-day point prevalence } \\
\text { abstinence at } 26 \text { weeks, } n(\%)\end{array}$ & $35(22.6)$ & $1500(42.7)$ & & 24.61 & $<0.001$ \\
\hline
\end{tabular}

Exchange rate: 1 US $\$=7.8 \mathrm{HK} \$$. 
related variables (Table 3 ), the following reasons to quit were predictors of abstinence: 'people around me hate me smoke' ( $p=0.027$, crude $\mathrm{OR}=2.38$ ), and 'want to improve my performance in exercises and sports' ( $p=0.005$, crude $\mathrm{OR}=4.78$ ). Amongst the psychosocial factors, smokers reported higher perceived confidence on quitting ( $\mathrm{p}=0.01$, crude $\mathrm{OR}=1.02)$. It was also found that clients who received more counselling sessions yielded better quit rates at 26 weeks.

All items that reported $\mathrm{p}<0.1$ in the univariate logistic regression analysis were included in the multiple logistic model with backward elimination. Only subjects with complete data in all fields of the included items were analyzed. The independent predictors of smoking abstinence at week 26 , shown in Table 4, were 'to improve performance in

Table 3. Univariate logistic regression analysis of sociodemographic and smoking-related variables $(\mathrm{N}=\mathbf{1 5 5})$

\begin{tabular}{|c|c|c|c|}
\hline & $\begin{array}{l}\text { Crude } \\
\text { OR }\end{array}$ & $95 \% \mathrm{CI}$ & $p$ \\
\hline \multicolumn{4}{|l|}{ Socio-economic variables } \\
\hline Age (years) & 1.00 & $0.97-1.04$ & 0.85 \\
\hline \multicolumn{4}{|l|}{ Sex } \\
\hline Female & 1 & Ref. & \\
\hline Male & 1.11 & $0.50-2.45$ & 0.80 \\
\hline \multicolumn{4}{|l|}{ Marital status } \\
\hline Separated/divorced/widowed & 1 & Ref. & \\
\hline Married/cohabiting & 1.21 & $0.55-2.66$ & 0.63 \\
\hline \multicolumn{4}{|l|}{ Employment status } \\
\hline Unemployed & 1 & Ref. & \\
\hline Employed & 1.30 & $0.61-2.77$ & 0.50 \\
\hline \multicolumn{4}{|l|}{ Education level } \\
\hline Junior secondary or below & 1 & Ref. & \\
\hline Senior secondary or above & 1.29 & $0.59-2.79$ & 0.53 \\
\hline \multicolumn{4}{|l|}{ Personal income (HK\$) } \\
\hline$<9999$ & 1 & Ref. & \\
\hline$\geq 10000$ & 1.20 & $0.47-3.11$ & 0.70 \\
\hline \multicolumn{4}{|l|}{ Alcohol use } \\
\hline \multicolumn{4}{|l|}{ Audit score } \\
\hline$>8$ & 1 & Ref. & \\
\hline$\leq 8$ & 2.43 & $0.29-20.1$ & 0.41 \\
\hline \multicolumn{4}{|l|}{ Smoking-related variables } \\
\hline Years of smoking & 1.01 & $0.98-1.04$ & 0.63 \\
\hline Smokers at home & 0.65 & $0.27-1.57$ & 0.34 \\
\hline Cigarettes per day & 0.97 & $0.93-1.01$ & 0.14 \\
\hline \multicolumn{4}{|l|}{ Fagerström score } \\
\hline High $(\geq 6)$ & 1 & Ref. & \\
\hline Moderate or below $(\leq 5)$ & 0.88 & $0.37-2.06$ & 0.76 \\
\hline
\end{tabular}

Table 3. Continued

\begin{tabular}{|c|c|c|c|}
\hline & $\begin{array}{l}\text { Crude } \\
\text { OR }\end{array}$ & $95^{\circ} \mathrm{CI}$ & p \\
\hline \multicolumn{4}{|l|}{ Reasons to quit } \\
\hline Prove it to myself & 0.95 & $0.42-2.14$ & 0.91 \\
\hline $\begin{array}{l}\text { To feel a sense of control over my } \\
\text { life }\end{array}$ & 1.09 & $0.46-2.58$ & 0.85 \\
\hline $\begin{array}{l}\text { Knowing someone being sick } \\
\text { because of smoking }\end{array}$ & 0.92 & $0.41-2.06$ & 0.83 \\
\hline Others want me to quit & 0.91 & $0.39-2.15$ & 0.83 \\
\hline $\begin{array}{l}\text { People around me hate smoking } \\
\text { (social influence) }\end{array}$ & 2.38 & $1.10-5.12$ & 0.027 \\
\hline Save money & 0.87 & $0.40-1.89$ & 0.72 \\
\hline To improve my appearance & 1.05 & $0.49-2.25$ & 0.90 \\
\hline $\begin{array}{l}\text { Want to improve my performance } \\
\text { in exercises and sports }\end{array}$ & 4.78 & $1.60-14.34$ & 0.005 \\
\hline $\begin{array}{l}\text { Avoid conflicts with family } \\
\text { members }\end{array}$ & 1.97 & $0.91-4.25$ & 0.09 \\
\hline $\begin{array}{l}\text { Avoid causing disputes at } \\
\text { workplace by smoking }\end{array}$ & 1.89 & $0.79-4.51$ & 0.15 \\
\hline Desiring a healthy life & 0.89 & $0.40-1.97$ & 0.77 \\
\hline Want to increase my weight & 1.39 & $0.26-7.52$ & 0.70 \\
\hline Being prejudiced by non-smokers & 1.52 & $0.57-4.01$ & 0.40 \\
\hline \multicolumn{4}{|l|}{$\begin{array}{l}\text { Self-assessment of efficacy in } \\
\text { quitting \& mental state }\end{array}$} \\
\hline Importance & 1.01 & $0.99-1.04$ & 0.22 \\
\hline Difficulty & 0.98 & $0.97-1.00$ & 0.06 \\
\hline Confidence & 1.02 & $1.01-1.04$ & 0.01 \\
\hline $\begin{array}{l}\text { Self-reported recent loss of } \\
\text { interest }\end{array}$ & 0.92 & $0.42-2.04$ & 0.84 \\
\hline $\begin{array}{l}\text { Self-reported recent depressed } \\
\text { mood }\end{array}$ & 0.97 & $0.45-2.12$ & 0.94 \\
\hline \multicolumn{4}{|l|}{ Interventional variable } \\
\hline Counselling sessions & 1.45 & $1.25-1.67$ & $<0.001$ \\
\hline
\end{tabular}

Exchange rate: $1 \mathrm{US} \$=7.8 \mathrm{HK} \$$

Table 4. Multiple logistic regression for predicting total abstinence at 26 weeks

\section{IOR $\quad 95 \% \mathrm{CI} \quad \mathrm{D}$}

\section{Reasons for quitting}

Have to improve my performance $\quad 4.74 \quad 1.29-17.39 \quad 0.019$ in exercises and sports

\section{Self-assessment of efficacy in quitting}

Confidence

$1.03 \quad 1.00-1.05 \quad 0.02$

Interventional variable

Counselling sessions $\quad 1.41 \quad 1.22-1.64<0.001$

AOR: adjusted odds ratio. 
exercise and sports' $(\mathrm{p}=0.019$, adjusted $\mathrm{OR}=4.74)$, confidence of quitting ( $\mathrm{p}=0.02$, adjusted $\mathrm{OR}=1.03$ ), and number of counselling sessions $(p<0.001$, adjusted $\mathrm{OR}=1.41$ ).

\section{DISCUSSION}

Despite high rates of smoking among people with psychotic disorders, and the associated health and financial burden, few studies have investigated the characteristics of this group of smokers. This study reports data from 155 smokers with psychotic disorder (schizophrenia, schizoaffective disorder, and affective disorder with psychosis) residing in the community. It included data on their demographic characteristics, smoking behaviour, severity of nicotine dependence, self-assessment of efficacy on quitting, reasons for quitting, and the use of alcohol.

In many western studies, detailed data relating to the behavioural domains of reasons for wanting to quit, alcohol dependence and level of nicotine dependence, self-assessment of efficacy and past history of quit attempts have not typically been collected from smokers with psychotic disorders ${ }^{8}$, and most studies have focused on schizophrenia.

Our study showed that in the psychotic group, there were more singles, less family income, presence of smokers at home, consuming more cigarettes per day with higher Fagerström score and lower AUDIT score, compared to the nonpsychotic group. This was in contrast to an Australian survey that indicated that the associations with current smoking in psychotic patients included low education, male gender, no formal employment, worse negative symptoms, and alcohol dependence ${ }^{8,16}$. In a study in China in patients with schizophrenia, smokers were more likely to have lower educational level, higher rate of divorce, heavier cigarette consumption, and higher nicotine dependence scores ${ }^{17}$.

In the current study, alcohol was used by only $34.8 \%$ of smokers with psychosis and the associated AUDIT score was very low. This was in contrast to the study by Howard ${ }^{18}$ in Canada where $47.3 \%$ of the cohort used alcohol and $10.1 \%$ had a history of alcohol dependence, or to the study by Vanable et al. ${ }^{19}$ in the US where $21 \%$ of participants $(n=568)$ were at risk for alcohol dependence (AUDIT score $>7$ ). This difference could be due to cultural difference ${ }^{19}$. Alcohol and illicit substance use are highly prevalent amongst people with psychosis and are associated with tobacco smoking and poorer health trajectories. Persistent alcohol use is associated with lower smoking cessation rates ${ }^{20}$. Less alcohol consumption of the subjects in the current study might explain better abstinence rates than studies from western countries. Even though alcohol use in our study was not as prevalent as in western countries, use of alcohol should still be addressed in the counselling process.

Overseas studies have identified that baseline characteristics such as older age at initiation of smoking, low level of nicotine dependence, high degree of motivation to quit, low nicotine dependence, low alcohol consumption, and longer duration of previous abstinence, have been associated with successful smoking cessation in the general population ${ }^{21-23}$. A study on predictors of abstinence in schizophrenia by Melissa et al. ${ }^{12}$ indicated that age, gender, marital status, education level, years of smoking, alcohol use, Fagerström score and having cohabiting smokers were not predictors of successfully abstinence. Similar to some overseas studies, univariate analysis of predictors of quitting in the current study did not reveal any association between basic demographics (age, gender, marital status, education level, employment status) or smoking behavior (years of smoking, cigarettes per day, Fagerström score, and having cohabiting smokers) with successful quitting. In contrast, selfconfidence in quitting and number of counselling sessions in intervention were significant predictors. In addition, the reported reasons to quit, i.e. social pressure/influence and wanting to improve performance in exercise and sports were other two significant predictors. This is in contrast with Baker et al. ${ }^{8}$ who reported significant predictors were social influence, self-control, extrinsic reasons such as immediate reinforcement (e.g. from money saved; no smell $)^{8}$. Saving money was not a predictor in the current study, probably because our subjects could buy cheaper smuggled cigarettes. Bader et al. ${ }^{24}$ stated that there is a striking lack of evidence about the impact of increasing cigarette prices on smoking behavior in heavy/long-term smokers with mental illness.

The independent predictors from a multivariate 
analysis were: wanting to have better performance in exercise and sport, greater confidence level, and number of counselling sessions. This may have implications in helping these smokers to quit: by boosting their motivation on improving exercise performance, building up their confidence by a flexible approach in intervention and providing close follow up, and adequate counselling sessions. The last one is echoed in the Addington et al. ${ }^{25}$ study, where there appears to be a dose-response relationship between abstinence rates and group attendance.

While many smokers with psychiatric illness would like to stop smoking, available research data indicate that smoking cessation rates among people with schizophrenia are quite low. The cessation rates reported in the de Leon et al. ${ }^{26}$ study were $9 \%$ for schizophrenia versus $14 \%$ to $49 \%$ for the general population. Despite the robust data demonstrating the efficacy of NRT in healthy individuals, relatively few clinical trials have assessed the efficacy of these treatments in individuals with psychiatric disorders. Cochrane remarked that the use of NRT patch for smokers with schizophrenia was tested in only a few trials with small sample sizes ${ }^{27}$. In a 10 -week study by George et al. ${ }^{28}$ evaluating the efficacy of a nicotine patch plus psychotherapy programme for smoking cessation in patients with schizophrenia or schizoaffective disorder, the combined smoking cessation rates for both treatment groups were approximately $35.5 \%$ at the end of treatment and approximately $14 \%$ at the end of a 6-month follow-up period. In our study, all participants preferred to use NRT instead of oral medication such as Varenicline for fear of side effects. With NRT and counselling, it yielded a better abstinence rate of $22.6 \%$ at 26 weeks. The cause for this difference is not apparent. It might be due to the fact that our counsellors were social workers who were trained on smoking cessation and the counselling sessions offered depend on the progress of intervention. Besides our subjects were not limited to smokers with schizophrenia. The current study has demonstrated the importance of adequate counselling. A previous study has showed that psychiatrists tend to offer limited counselling on smoking related health risks to patients with mental illness ${ }^{29}$. Hence, it is worth raising the awareness of medical staff to treat nicotine addiction for mentally ill patients or to refer these patients to services specialized in smoking cessation service.

\section{Limitations}

There were limitations in our study. The main limitation was the chart review nature of the study. The subjects were outpatients with psychotic disorder and their mental status was relatively stable. They are a cohort from a smoking cessation program that was not designed specifically for individuals with psychiatric illness. The findings cannot be generalized to the whole psychotic population. The participants were more motivated to quit smoking because most were self-referred to our clinics. We have not included the effects of psychotic medication, negative symptoms and psychosocial functioning for predictor analysis or evaluated the effectiveness of oral medications. Selfreported 7-day point prevalence abstinence rate was not biochemically validated, although a previous study indicated that self-reported abstinence does not differ much from biochemical validation ${ }^{30}$.

\section{CONCLUSIONS}

Smokers diagnosed with psychosis are motivated to quit ${ }^{31}$. Even though their success rates are more modest than those without mental illness, there are definite means to help them quit. WHO has recommended that health professionals need to pay much greater attention to tobacco use by individuals with mental disorders ${ }^{32}$. Every effort should be given to enhance their motivation, build up their confidence and provide adequate counselling sessions, as their smoking behaviour is directly contributing to a significantly increased morbidity and mortality in this population.

\section{REFERENCES}

1. Brown S, Kim M, Mitchell C, Inskip H. Twenty five year mortality of a community cohort with schizophrenia. Br J Psychiatry. 2010;196(2):116-121. doi:10.1192/bjp.bp.109.067512

2. Chapman S, Ragg M, Mc Geechan K. Citation bias in reported smoking prevalence in people with schizophrenia. Australian and New Zealand Journal of Psychiatry. 2009;43(3):277-282. doi:10.1080/00048670802653372

3. de Leon J, Diaz FJ. A meta-analysis of worldwide studies demonstrates an association between schizophrenia and tobacco smoking behaviours. Schizophr Res. 2005;76(23):135-157. doi:10.1016/j.schres.2005.02.010 
4. Kumari V, Postma P. Nicotine use in schizophrenia: the self medication hypotheses. Neurosci Biobehav Rev. 2005;29(6):1021-1034. doi:10.1016/j.neubiorev.2005.02.006

5. Wing VC, Wass CE, Soh DW, George TP. A review of neurobiological vulnerability factors and treatment implications for comorbid tobacco dependence in schizophrenia. Ann N Y Acad Sci. 2012;1248(1):89-106. doi:10.1111/j.1749-6632.2011.06261.x

6. Ziedonis DM, Williams JM. Addressing tobacco use in mental health and addiction settings. Psychiatr Ann. 2003;33(7):425426. doi:10.3928/0048-5713-20030701-04

7. Ziedonis D, Hitsman B, Beckham JC, et al. Tobacco use and cessation in psychiatric disorders: National Institute of Mental Health report. Nicotine Tob Res. 2008;10(12):16911715. doi:10.1080/14622200802443569

8. Baker A, Richmond R, Haile M, et al. Characteristics of smokers with a psychotic disorder and implications for smoking interventions. Psychiatry Res. 2007;150(2):141152. doi:10.1016/j.psychres.2006.05.021

9. Wehring HJ, Liu F, McMahon RP, Mackowick KM, Love CR, Dixon L. Clinical Characteristics of Heavy and Non-Heavy Smokers with Schizophrenia. Schizophr Res. 2010;138;(23):285-289. doi:10.1016/j.schres.2012.03.024

10. Herrán A, de Santiago A, Sandoya M, Fernández MJ, Diez-Manrique JF, Vázquez-Barquero JL. Determinants of smoking behaviour in outpatients with schizophrenia. Schizophr Res. 2000;41(2):373-381. doi:10.1016/s0920-9964(99)00082-1

11. Filia SL, Baker AL, Gurvich CT, Richmond R, Lewin TJ, Kulkarni J. Gender differences in characteristics and outcomes of smokers diagnosed with psychosis participating in a smoking cessation intervention. Psychiatry Res. 2014;215(3):586-593. doi:10.1016/j.psychres.2014.01.002

12. Culhane MA, Schoenfeld DA, Barr RS, et al. Predictors of Early Abstinence in Smokers with Schizophrenia. J Clin Psychiatry. 2008;69(11):1743-1750. doi:10.4088/jcp.v69n1109

13. Fiore MC, Jaén CR, Baker TB, et al. Treating Tobacco Use and Dependence: 2008 Update. Rockville, MD: U.S. Department of Health and Human Services, Public Health Service; 2008.

14. Chan SSC, Lam TH. An evaluative study of the integrated smoking cessation services of Tung Wah Group of Hospitals. Hong Kong, China: Tung Wah Group of Hospitals; 2011.

15. Miller, W. R., \& Rollnick, S. Motivational Interviewing: Preparing People for Change. 2nd ed. New York, NY: The Guilford Press; 2002.

16. Cooper J, Mancuso SG, Borland R, Slade T, Galletly C, Castle D. Tobacco smoking among people living with a psychotic illness: The second Australian survey of psychosis. Aust N Z J Psychiatry. 2012;46(9):851-863. doi:10.1177/0004867412449876

17. Tang YL, George TP, Mao PX, Cai ZJ, Chen Q. Cigarette smoking in Chinese male inpatients with schizophrenia:
A cross-sectional analysis. J Psychiatr Res. 2007;41(12):43-48. doi:10.1016/j.jpsychires.2005.10.009

18. Margolese HC, Malchy L, Negrete JC, Tempier R, Gill K. drug and alcohol use among patients with schizophrenia and related psychosis: levels and consequences. Schizophr Res. 2004;67(2-3):157-166. doi:10.1016/S0920-9964(02)00523-6

19. Vanable PA, Carey MP, Carey KB, Maisto SA. Smoking Among Psychiatric Outpatients: Relationship to Substance Use, Diagnosis, and Illness Severity. Psychol Addict Behav. 2003;17(4):259-265. doi:10.1037/0893-164x.17.4.259

20. de Leon J, Rendon DM, Baca-Garcia E, Aizpuru F, Gonzalez-Pinto A, Anitua C, Díaz FJ. Association between smoking and alcohol use in the general population: Stable and unstable odds ratios across two years in two different countries. Alcohol Alcohol. 2007;42(3):252-257. doi:10.1093/alcalc/agm029

21. Etter JF, Prokhorov AV, Perneger TV. Gender differences in the psychological determinants of cigarette smoking population. Addiction. 2002;97(6):733-743. doi:10.1046/ j.1360-0443.2002.00135.x

22. Chandola T, Head J, Bartley M. Socio-demographic predictors of quitting smoking: how important are household factors? Addiction. 2004;99(6):770-777. doi:10.1111/j.1360-0443.2004.00756.x

23. Ferguson JA, Patten CA, Schroeder DR, Offord KP, Eberman KM, Hurt RD. Predictors of 6-month tobacco abstinence among 1224 cigarette smokers treated for nicotine dependence. Addict Behav. 2003;28(7):12031218. doi:10.1016/S0306-4603(02)00260-5

24. Bader P, Boisclair D, Ferrence R. Effects of Tobacco Taxation and Pricing on Smoking Behavior in High Risk Populations: A Knowledge Synthesis. Int J Environ Res Public Health. 2011;8(11):4118-4139. doi:10.3390/ijerph8114118

25. Addington J, Nady el-Guebaly, Campbell W, Hodgins DC, Addington D. Smoking cessation treatment for patients with schizophrenia. Am J Psychiatry. 1998;155(7):974976. doi:10.1176/ajp.155.7.974

26. de Leon J, Diaz FJ, Rogers T, Browne D, Dinsmore L. Initiation of daily smoking and nicotine dependence in schizophrenia and mood disorders. Schizophr Res. 2002;56(1-2):47-54. doi:10.1016/S0920-9964(01)00217-1

27. Tsoi DT, Porwal M, Webster AC. Interventions for smoking cessation and reduction in individuals with schizophrenia. Cochrane Database Syst Rev. 2013;(2):CD007253. doi:10.1002/14651858.CD007253.pub3

28. George TP, Ziedonis DM, Feingold A, et al. Nicotine transdermal patch and atypical antipsychotic medications for smoking cessation in schizophrenia. Am J Psychiatry. 2000;157(11):1835-1842. doi:10.1176/appi.ajp.157.11.1835

29. Himelhoch S, Daumit G. To whom do psychiatrist offer smoking cessation counselling? Am J Psychiatry. 2003;160(12):2228-2230. doi:10.1176/appi.ajp.160.12.2228 30. Patrick DL, Cheadle A, Thompson DC, Diehr P, Koepsell 
T, Kinne S. The validity of self-reported smoking, a review and meta-analysis. Am J Public Health. 1994;84(7):10861093. doi:10.2105/ajph.84.7.1086

31. Siru R, Hulse GK, Tait RJ. Assessing motivation to quit smoking in people with mental illness: a review. Addiction. 2009;104(5):719-733. doi:10.1111/j.1360-0443.2009.02545.x

32. World Health Organization. The World health report : 2001 : Mental health : new understanding, new hope. Geneva, Switzerland: World Health Organization; 2001. https://apps.who.int/iris/handle/10665/42390. Accessed September 23, 2019.

ACKNOWLEDGEMENTS

We are indebted to Bandai WC Choi for his statistical input.

CONFLICTS OF INTEREST

The authors have completed and submitted the ICMJE Form for Disclosure of Potential Conflicts of Interest and none was reported.

FUNDING

There was no source of funding for this research.

PROVENANCE AND PEER REVIEW

Not commissioned; externally peer reviewed. 